\title{
A problem-based learning resource in emergency medicine for medical students
}

Anne-Maree Kelly

\begin{abstract}
Emergency medicine is a relatively new specialty area within medicine, however medical schools, students and standard setting bodies have recognised that learning emergency medicine is integral to the training of medical students. There are, however, significant problems with the delivery of emergency medicine teaching including low teacher numbers, severely limited teaching time and lack of suitable learning resources. This paper describes the process of development of a learning resource, its format and content and summarises student feedback.

(F Accid Emerg Med 2000;17:320-323)
\end{abstract}

Keywords: education; emergency medicine

Emergency medicine is a relatively new specialty area within medicine and, in comparison with other disciplines, the number of specialist emergency physicians is quite small. At the same time, medical schools, students and standard setting bodies, such as the Australian Medical Council ${ }^{1}$ and the Postgraduate Medical Council of New South Wales ${ }^{2}$ have recognised that learning the principles of emergency medicine is essential for medical students.

But there are problems with providing

Department of Emergency Medicine, Western Hospital, Private Bag, Footscray 3011, Australia

Correspondence to: Professor Kelly (Anne-Maree.Kelly@, nwhcn.org.au)

Accepted 29 February 2000

suitable teaching. High clinical loads and limited emergency physician numbers make time available for teaching short. Additionally, in most medical schools, the number of hours allocated to the teaching of emergency medicine are meagre. ${ }^{34}$ This serious mismatch between increasing demands for emergency medicine teaching and finite resources is compounded by the fact that many teaching programmes in the field have developed in an ad hoc manner without suitable learning resources. These problems are not isolated to Australasia. Evidence from the United Kingdom and USA suggests that they are grappling with similar issues. ${ }^{4-6}$

The aim of this project was to tackle some of these problems by developing a learning resource for use by students, either as the basis for tutorials or for independent learning.

\section{Educational basis}

The underlying philosophies of the study guide format are based upon sound educational principles. Research has shown that knowledge is better recalled in the context in which it was originally learned $^{7-10}$ and that the application of new knowledge in activities such as discussion, answering questions and solving problems leads to better understanding and retention of knowledge. ${ }^{891112}$ The strong focus of the study guide is on problem-based learning, student participation and the development of decision making skills. It was designed so that it could form the basis for interactive small group tutorials or be used by students for independent learning. Independent learning permits students to learn at their own pace, decide areas on which they needed to spend more time, develop research skills for learning, and develop the habit of self directed learning for their professional lives.

\section{Content and style}

Given the breadth of emergency medicine, definition of a core curriculum was difficult. Attempts to do so have been made by The Society of Teachers of Emergency Medicine (USA), ${ }^{13}$ The Society for Academic Emergency Medicine (USA) ${ }^{14}$ and The Australasian College for Emergency Medicine. ${ }^{15}$ The 10 topics chosen for the initial study guide fell into three main groups: the relationship between

Table 1 Topic sections in the study guide

\begin{tabular}{|c|c|c|}
\hline First edition & Second edition & Third edition \\
\hline $\begin{array}{l}\text { The emergency department, the community and the } \\
\text { hospital } \\
\text { Triage } \\
\text { Abdominal pain } \\
\text { Chest pain } \\
\text { Extremity injuries } \\
\text { Altered level of consciousness } \\
\text { Trauma } \\
\text { Poisoning } \\
\text { Acute shortness of breath } \\
\text { Pain }\end{array}$ & $\begin{array}{l}\text { The emergency department, the community and the } \\
\text { hospital } \\
\text { Triage } \\
\text { Abdominal pain } \\
\text { Extremity injuries I and II } \\
\text { Altered level of consciousness } \\
\text { Trauma } \\
\text { Poisoning } \\
\text { Acute shortness of breath } \\
\text { Pain } \\
\text { Cardiac emergencies } \\
\text { Burns } \\
\text { Diabetic emergencies } \\
\text { Paediatric emergencies } \\
\text { Miscellaneous-including environmental }\end{array}$ & $\begin{array}{l}\text { The emergency department, the community and the } \\
\text { hospital } \\
\text { Triage } \\
\text { Abdominal pain } \\
\text { Extremity injuries I and II } \\
\text { Altered level of consciousness } \\
\text { Trauma } \\
\text { Poisoning } \\
\text { Acute shortness of breath } \\
\text { Pain } \\
\text { Cardiac emergencies } \\
\text { Burns } \\
\text { Diabetic emergencies } \\
\text { Paediatric emergencies } \\
\text { Miscellaneous-including environmental } \\
\text { Medicolegal aspects } \\
\text { Knowing your ED } \\
\text { Obstetric and gynaecology }\end{array}$ \\
\hline
\end{tabular}




\section{CASE FOUR (from section 17: Paediatric emergencies)}

Sian is a 10-month-old breast-feeding baby. She has 24 hours of diarrhoea and vomiting.

She tries to feed but "falls off" the breast after 2-3 minutes. She is easily rousable but appears disinterested.

-What are the differential diagnoses of this problem?

- How would you assess Sian's hydration status? How reliable are these?

- Assuming that Sian is mildly dehydrated, outline your management.

\section{CASE ONE (from section 6: Extremity injuries I)}

Mr. $\mathrm{K}$ is a handy man. One afternoon, while cleaning windows, he has a fall and his right arm strikes and breaks a window. On initial examination, Mr. K has a $5 \mathrm{~cm}$ transverse laceration to the flexor aspect of his right wrist.

-What structures are at risk?

- How would you test for the integrity of these structures?

-What is the role of examination of the wound floor and contents?

\section{CASE ONE (from section 13: Diabetic emergencies)}

Ben, aged 20, is playing football. He is a known diabetic, taking twice daily insulin. Last night he had a "big" night with his mates and got quite drunk. Today's game is tougher than he expected. At half time Ben feels tired, but puts it down to the game and last night's beer! About ten minutes into the second half his team mates notice that Ben seems to have lost concentration. Five minutes later he begins to stagger and falls to the ground.

-What is the most likely cause of Ben's collapse?

- List at least three factors that may have contributed to the development of this condition.

-What are the clinical signs of hypoglycaemia? How are they modified by beta blocker therapy?

- Outline your management of Ben (short term for this episode and for prevention of similar episodes in the future).

Figure 1 Examples of problem-based learning exercises.

the emergency department (ED), the community and the hospital; common medical and surgical problems seen in EDs and problems for which emergency medicine has special expertise. A deliberate attempt was made not to overwhelm students with too much information, instead concentrating on relationships and the principles of common and important topics. The 10 topics chosen for the first edition are shown in table 1.

For each topic, a limited number of specific learning objectives are provided. They concentrate on the link between basic and clinical science and the principles of decision making and treatment in the ED. Sections were designed with the aim that the activities contained could be completed by students within 45 to 60 minutes.

The main activity in the study guide is the use of realistic case scenarios, supported by a series of questions to bring out the major issues. Examples of problem scenarios are shown in figure 1. In addition, to provide variety and maintain interest, some novel activities were also included, such as crossword puzzles, diagrams for completion, multiple choice questions and extended matching items. These activities also served as exercises in reinforcement of learning. An example is shown in figure 2 .

When used as the basis for tutorials, students were instructed to work through relevant sections before attending the tutorial so that tutorial time could be used for checking learning and discussion and reinforcement of important points.

\section{Evolution}

A formal process of evaluation of the first edition was conducted in 1995 by fourth and final year students of The Royal Melbourne Hospital-Western Hospital Clinical School. Feedback from students was very positive about format, content and usefulness in directing learning. Several suggestions were made for the inclusion of additional topic areas: these included diabetic ketoacidosis, cardiac emergencies, burns, cervical spine radiographs, environmental emergencies and fracture management. Activities that students found particularly useful were the case scenarios and 
matching questions. Suggestions for improvement included the provision of answers to the MCQ and matching questions and the identification of suitable reference resources.

In response to student feedback, new sections on fractures, diabetic emergencies, burns, cardiac emergencies and environmental emergencies were added to the second edition of the study guide (table 1 ).

The second edition has been in use since 1997. In addition to the ED at Western Hospital, it has been used by other teaching EDs in
Australia, Southern Africa and Asia. Further feedback from students and teachers has resulted in a third edition (released February 2000, copies available from the author on request) in which all sections have been revised and updated and sections on medicolegal aspects and obstetrics and gynaecology added (table 1).

\section{Comment}

The process of design of this learning resource was very challenging, partly because it is an

\section{Activity:}

With your knowledge of anatomy and pathology, attempt to complete this diagram which gives a differential diagnosis of acute abdominal pain by location.

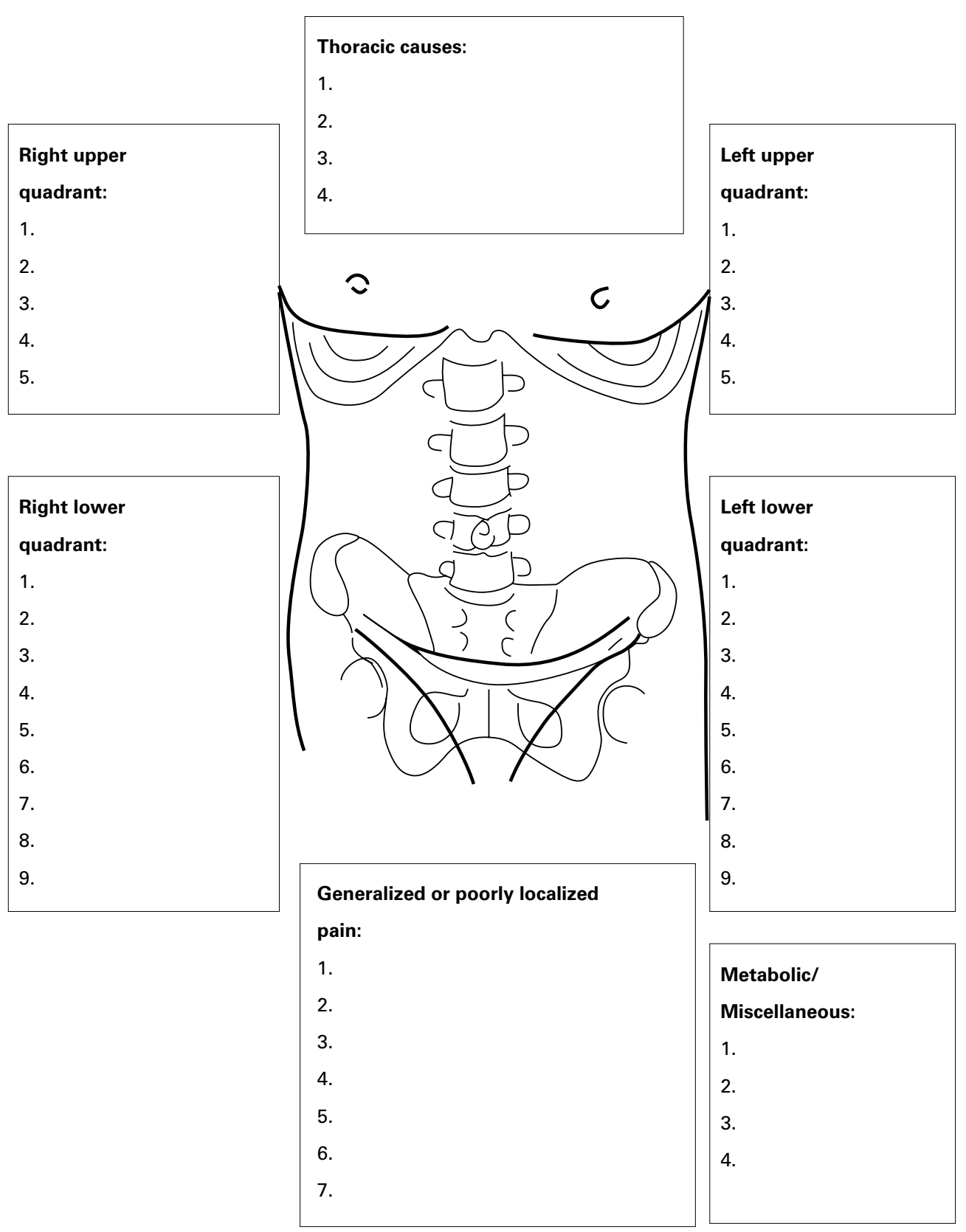

Figure 2 Example of learning activity. 
unusual form of "text" for medical students. The support from students, both for the study guide and the process of preparation for tutorials, has continued to be strong. The study guide has also proved to be flexible, working equally well for fourth and final year students and for different lengths of ED attachment.

This style of learning resource would lend itself well to an interactive computer and webbased program, which would allow more interactive activities. It is hoped that this adaptation will be possible in the not too distant future.

\section{Conclusion}

The development of this problem-based study guide has been a unique and innovative attempt to match students' need and keenness to learn emergency medicine, the resource limitations of modern EDs and sound educational principles.

Funding: none.

Conflicts of interest: none.

1 Accreditation Committee of the Australian Medical Council. The assessment and accreditation of medical schools in Australia. Canberra: Australian Medical Council 1992.

2 The Postgraduate Medical Council of New South Wales. Postgraduate medical training during internship and residency: aims and objectives of the internship and general medical residency. Sydney: The Council. 1990.
3 Kelly AM. Undergraduate teaching of emergency medicine in Australasia. Emergency Medicine 1992;4:106-9.

4 Binder L, Emerman C, Tackakra S, et al. Undergraduate education in emergency medicine. Ann Emerg Med 1990;19:1152-80.

5 Gibson MF, Clancy MJ. Undergraduate medical student education: the case for a national curriculum. Arch Emerg Med 1990;7:215-19.

6 Sanders AB, Criss E, Witzke D. Survey of undergraduate medical education in the United States. Ann Emerg Med 1986;15:1-5.

7 Claesson HFA, Boshuizen HPA. Recall of medical information by students and doctors. Med Educ 1985;19:61-7.

8 Norman GR. Problem solving skills, solving problems and problem based learning. Med Educ 1988;22:279-86.

9 Norman GR, Schmidt HG. A psychological basis of problem based learning: A review of the evidence. Acad Med 1992;67:557-62.

10 Schmidt HG. Problem based learning: rationale and description. Med Educ 1983;17:11-16.

11 Albanese MA, Mitchell S. Problem based learning: A review of the literature on its outcomes and implementation issues. Acad Med 1993;68:52-81.

12 Coles R. Evaluating the effects curricula have on student learning: Towards a more competent theory for medical education In: Nooman ZM, Schmidt HG, Ezzat ES, eds. Innovations in medicine: an evaluation of its present status. New York: Springer, 1990

13 Society of Teachers of Emergency Medicine. Core content for undergraduate education in emergency medicine. Ann Emerg Med 1985;14:474-6.

14 American College of Emergency Physicians. Guidelines for undergraduate education in emergency medicine. Ann Emerg Med 1987;16:117-19.

15 Australasian College for Emergency Medicine Undergraduate Education Committee. Policy for the emergency medicine component of the undergraduate medical curriculum. Emergency Medicine 1994;6:141-4. 